\title{
Encouraging Women Entrepreneurship In Pakistan: A Systematic Analysis Of The Impact Of Entrepreneurial Activities On The Lifestyle Of Women
}

\author{
Samina Rauf \\ Department of Social Work \\ University of Karachi \\ Nasreen Aslam Shah \\ Women's Studies \\ University of Karachi
}

\begin{abstract}
Considerable researcher has been carried out for the identification of the barriers faced by women entrepreneurs in Pakistan and how these barriers can be removed. Moreover, the research has also attempted to establish the impact of entrepreneurial activities on the lifestyle of women. Qualitative research technique has been employed for the analysis of the data. It was established from results obtained that after starting the business, lifestyle of women entrepreneurs has improved substantially.

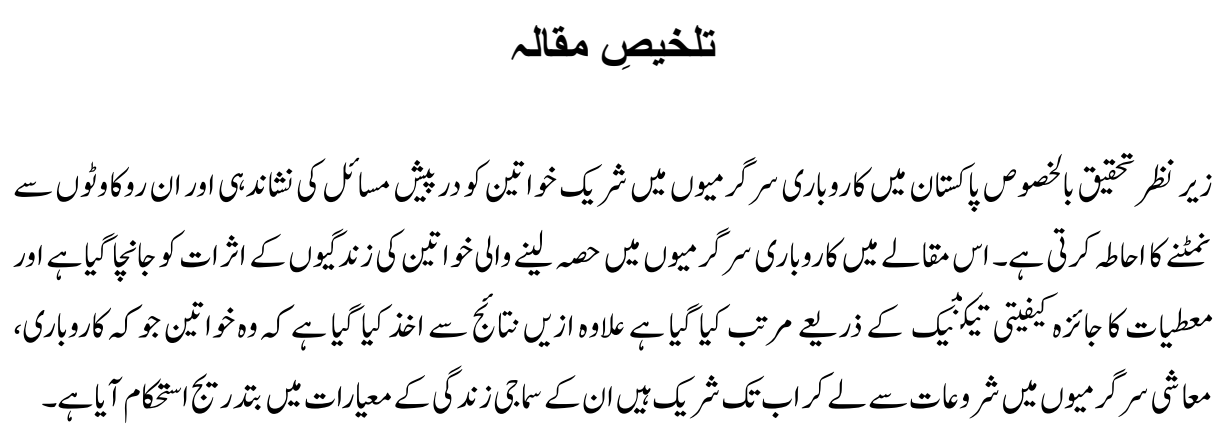

\section{Introduction}

At present, there is an evident increase among women entrepreneurs all over the world, which now accounts for more than a quarter to a third of the businesses operating in the formal economy. However, majority of women entrepreneurs are engaged in small or micro enterprises with limited options for expansion. On the other hand, women entrepreneurs are mostly underrepresented in every organization, whether small, medium or large. In fact, the bigger the firm the lesser chances are there that it will be headed by a woman. Social beliefs and societal attitudes prevent some women from formally starting their own business, whereas, systematic obstructions are there to confined majority of the women entrepreneurs to operate small businesses in informal economy in the developing world. This at the one 

Entrepreneurial Activities on the Lifestyle of Women

hand restrict the ability of the women entrepreneurs to earn a generous income for their families and for themselves, but on the other hand this also restrain women entrepreneurs to effusively contribute their efforts in the socio-economic development of the country.

\section{Aim of this Study}

The aim of this study is to identify the barriers which hinder the growth and development of women entrepreneurship in Pakistan along with systematic examination of the impact of entrepreneurial activities on the lifestyle of women.

\section{Significance of the Study}

Considerable researchers have been carried out for the identification of the barriers faced by women entrepreneurs in Pakistan and how these barriers can be removed. This research will also attempt to establish the impact of entrepreneurial activities on the lifestyle of women. There is a scarcity of literature in context of Pakistan, which can identify how entrepreneurship is changing the lifestyle of the women in the country. Therefore, this research is important as it not only identifies the impact of entrepreneurial activities on lifestyle of women, but will also propose a solution to the major barriers which limit the growth of women entrepreneurship in Pakistan.

\section{Literature Review \\ Entrepreneurship for Women}

Considerable research has been carried out to identify the main barriers which restrict the growth and development of women entrepreneurship in Pakistan. Moreover, the study also aims to explore how engagement in entrepreneurial activities affects the lifestyle of women. Therefore, it is pertinent to discuss what entrepreneurship actually means in context of women, and how do they perceive it. The term entrepreneurship basically refers to the vision or idea hold by women; and they aim to further discover and optimize it, which at the one hand empower women entrepreneurs in economic context, while on the other entrepreneurship help them to create more job. Despite the fact that the society in which we are living is male dominated, yet women from all over the world have demonstrated positive signs of entrepreneurial spirit. In this context, it is expected from the government institution to extend their support to women entrepreneurs at every level in order to encourage more women to assume the role of entrepreneurs. According to the GEM Report (2007) more than 200 million women are working all over the world contributing in every industry, while the report also identifies that over 100 million women are from developing countries.

Entrepreneurship for women in developing countries, especially in Pakistan means that women are in control of their life, without depending on someone (Gundry, Yoseph and Posig, 2002). However, the fact remains that empowering women is the main barrier, 
which is not being widely accepted and encouraged in Pakistan's society. Therefore, majority of the women who are willing to make their contribution to their families and eventually to the economy remain confined to their house (Kalim, 2012). However, women not being considered as a workforce by the society; is actually the potential barrier, which is why a large number of women are hesitant to step out of their home. Moreover, women entrepreneurs who take the initiative also had to face extensive pressure from the family, society and community. However, societal or family pressure is not the only barrier, but there are others which are discussed in the following discussion, which keeps potential women entrepreneurs away in developing countries (Hisrich and Ozturk, 1999).

However, in accordance with (Kalim, 2012) gender equality in developed countries is higher, which provides women entrepreneurs a platforms to present their talent. Even the gender equality is higher, but women in developed countries also face certain financial insecurities, challenges to find potential human resource among others compare to their male counterparts, which are essential for a successful business.

\section{Factors to Motivate Woman Entrepreneurs}

Despite all the barriers, contemporary business trends have been considered nourishing for entrepreneurs; therefore increase in the amount of entrepreneurs all across the world is evident (Kalim, 2012). Managing and operating large corporations, in every form, is challenging; thus small and medium sized business formats are widely popular among new entrepreneurs (Carter and Jones, 2006). Factors that motivate women entrepreneurs to start their business are of two types: a) entrepreneurs by choice; b) entrepreneurs by need (Schumpeter, 2000). These two motivational factors can be broken down further into the different factors which are given below.

Women who by choice become entrepreneurs are motivated by the following elements:

- To formulate their vision or idea into capital

- To be empowered and independent

- To demonstrate their value before their family members; especially male

- To work on their own set of rules without taking dictation from anyone

- To take control of the areas where they lack during their job or any past experience

- To fulfill a long hold wish to run and operate own company

- To satisfy their need that working from someone else will not be beneficial

Women who become entrepreneurs by necessity are normally motivated by the following elements:

- To enhance the quality of their life and the life of their children

- To make contribution in the family by reducing their economic burden

- To become bread earner for their family, while having no one to support their financial needs 

Entrepreneurial Activities on the Lifestyle of Women

- To live the life on their own terms with success, while managing and adjusting their business and household

However, besides the two motivational factors types defined above, there are few secondary factors which motivate entrepreneurship among women, including: the desire of women to be treated fair in the society and in workplace; and past experience that is also accounted as motivational factor, which in fact has been considered as one of the most crucial factors for the success of any start-up.

Furthermore, there are different cultural factors, which stimulates favourable behaviour of women towards entrepreneurship, like socio-economic elements, self-confidence, monetary gains, contribution to the society, ideas materialization and bringing out creativity and innovation.

\section{Contemporary Situation of Women Entrepreneurs in Developing Countries}

Traditionally, in developing countries where birth rates are higher have more existence of female entrepreneurs compare to developed and developing countries where birth rate are low. Moreover, the traditions, beliefs and customers have extensive influence on the choice of a woman to become entrepreneur (Esperança, Hill \& Valente, 2006).

In general, women are not provided equal employment and training opportunities in low income countries, and even if they managed to get jobs, they are less likely to afford health and child care. Whereas, employers on the other hand are unable to provide favourable working conditions for women due to low rate of women workforce; and if provided, it will be considered additional economic burden on the business. This is because women have to take care of their families and children, despite the fact that they are working. From the perspective of employers in developing countries, hiring women is normally interpreted as less attendance, more demands, health insurance among others (Muhammad, 2008). The fact however works as an incentive for women, which encourage their efforts to become entrepreneurs rather than obtaining employment. Women normally start businesses which benefit them in monetary terms as well as in terms of providing care and support to their families (Gem Report, 2004).

This entrepreneurial behaviour among women is further strengthened by the lack of involvement of fathers in providing care to the children. Therefore, women in developing countries mostly go for the nature of business which they can easily operate from their home (Brush, Carter and Gatewood, 2006).

\section{Contemporary Situation of Women Entrepreneurs in Developed Countries}

The problem of business growth is relatively significant among women entrepreneurs in developed or high-income countries, where women are entering more and more in 
technology based businesses. If businesses which are being operated or managed by women entrepreneurs are compare with the businesses owned by male, it is become evident that business operated by women tend to grow very slowly and are smaller in size (Shane and Venkataraman, 2000). In fact, even in developed countries women faces certain issues related to raising finance for their business and demonstrating their credibility as owner and managers of business. Furthermore, socializing with other people is an additional barrier and women even in developing and developed countries lack business contacts. These barriers are considered as the disadvantage for women and result in decreasing the growth rates of women entrepreneurs (Bowen, and Hisrich, 1986). In fact, according to GEM Report (2007) social scientists are now increasingly believed that the growth of a business is partially determined by the motivation level of entrepreneurs. Therefore, it can be said that reason which motivates women for starting their business is to some extent determinant factor for their business growth. Therefore, it can be said that women who start their business just to support the financial needs of their family may not consider extending their business beyond to a certain point where their financial needs are adequately satisfied. In this connection, it can be said that business growth difference basically lies in accordance with the method of expansion adopted.

\section{Perceptions of Women in Pakistan}

The report by the World Bank Country Gender Profile of Pakistan identified that women's status in Pakistan is considered among the lowest as compared to the other countries of the world. In relation to this, the report by UNDP (1996) highlights the strong dichotomy of "inside / outside" in Pakistan, as women in Pakistan are mostly confined to the inside world to perform their gender specific role of taking care of the household chores, combined with covering the face with veil. This in turn restricts the movement of women in Pakistan for entering in education, employment and almost every other field. Samina Kamal (1997) in this connection describe another important factor that the societal disapproval of the working women at mass level can be interpreted as eliminating women from the labour force of Pakistan. Though, women actively take part in the farming affairs and other small family owned business, their contribution is normally overlooked as their duty towards the family, rather than giving their efforts due consideration as economic contribution (Goheer, 2003).

\section{Barriers to Women Entrepreneurs in Pakistan}

For the socio-economic development of the country, women are considered an integral part of the due process. At present, more than $50 \%$ population of the Pakistan comprises of women, and they are playing a vital, constructive and positive role in the development of the country. The role of the women in Pakistan is becoming very much productive, since they are effectively participating in agriculture, industrial and service sector while getting recognitions for working on site and even from their home. In fact, in every sector of Pakistan, women are playing important role, though they are less in headcounts compare to their male counterparts 

Entrepreneurial Activities on the Lifestyle of Women

(Goheer, 2003). To further increase the social and economic contribution of women, it is believed that women should be empowered and emancipated; and women entrepreneurship emerges as the best technique for it. There are numerous benefits of encouraging women entrepreneurship in Pakistan; in fact the economic situation of the country will thrive if women are being facilitated with same opportunities as men. Yet! There are number of barriers which impede the encouragement of women entrepreneurship in Pakistan (Goheer, 2003).

In connection to barriers faced by women entrepreneurs in Pakistan, a study conducted by British Journal of Education, Society \& Behavioral Science provides vital information (Mahmood, Sohail, Khalid et al., 2012). The research identifies gender specific barriers, which restrict the entry of women entrepreneurs from frontline entrepreneurship in the country. The study was carried out during a period of 6 to 8 months in four different cities of Pakistan's Punjab province including Lahore, Faisalabad, Sialkot and Sargodha. The results of the study identified some of the common social and cultural barriers which affect women entrepreneurship in Pakistan, including: mobility restrictions, scarcity of financial resources, no one to guide, lack of role models, male dominated markets, pressure from family and gender discrimination among others. City-wise classification of the barriers highlights that respondent of Faisalabad points towards, no access to financial resources, mobility restrictions, dependent decision making, burden of family and child care and pressure from family as the main barriers. The results of Lahore, Sargodha and Sialkot were quite similar, but variance in some aspect likes rights for property, communication gap, lack of education and sexual harassment were also added as the main barriers for encouraging women entrepreneurship (Mahmood, Sohail, Khalid et al., 2012).

The report by British Journal of Education, Society \& Behavioral Science identified lack of financial resources as the main barrier for women in starting their business. This barrier has also been endorsed by the fact presented in the report of World Bank that less than 25 percent of the women entrepreneurs in Pakistan borrow money from microfinance industry (Mahmood, Sohail, Khalid et al., 2012). Despite the fact that microfinance industry of Pakistan is very much progressive in nature, only handful amount of women have knowledge or awareness regarding micro-finance loans. However, awareness is not the main cause of money not being borrowed by women entrepreneurs but the discrimination in the lending practice is. This discrimination compels women entrepreneurs to look of other options to obtain required capital for their business.

Moreover, the report of World Bank also made the revelation that loans are mostly not granted by micro-finance corporations to women entrepreneurs, in particular to unmarried women, as they are considered borrower of high risk. Moreover, the regulations of microfinance institutions have made such requirements that without a man, a women entrepreneur may not be granted the loan (World Bank, 2012). The report identifies the major drawback of the micro-finance institution, as $68 \%$ of the women are required to obtain the permission of any male of the family in order to get their loan approved. 
The World Bank report further identifies that micro-finance institutions demand guarantee from two male, in order to approve the business loan. In fact, one of the guarantors should not be related to the borrower. This added misery to the burdens faced by women entrepreneurs as women in Pakistan are not allowed to mingle up with unknown people of opposite sex. Therefore, it becomes difficult for the women entrepreneurs to find unrelated male, which eventually deprive them from accessing loans (World Bank, 2012).

The report by the World Bank not only identifies the solution of the financial resources for women entrepreneurs but also the recommendations will help the micro-finance industry to increase its global reach and will help the industry in establishing itself as a market leader of the world. Investing in awareness programs which provide financial literacy to women entrepreneurs is one part of the solution, combined with specially designed products for women entrepreneurs so that they can support, sustain and grow their business. Whereas, the report also suggest that State Bank of Pakistan as a financial regulator should introduce policies and procedures which discourage discrimination in provision of loans. Moreover, State Bank of Pakistan should also provide consumer protection to women borrowers as to easy the process of obtaining loan (World Bank, 2012).

\section{Method of Research}

Qualitative research is normally perceived as an umbrella term under which different collection of attitudes and method of inquiries falls. Qualitative research technique is considered appropriate for exploring how human beings experience, learn, interpret, understand and develop their social world (Keeves, 1997). History, literary criticism, culture, material-culture studies and ethics are among the important examples of the subjects which are believed to be explained completely by qualitative research. Concluding the essence of qualitative technique of research, it can be claimed that qualitative research tends to obscure, both, differences and commonality. The main reason for which a research project is given the title of qualitative research lies in the presentable efforts of the research for producing rich, related and comprehensive interpretation of the people, linguistic, material, social and other practices and events (Kothari, 2004). In accordance with the nature of the subject under study, it has been established that by following qualitative research methodology researcher can draw appropriate results. Moreover, the above definition of the qualitative technique also helps in backing the researcher's choice of methodology.

\section{Data Collection and Analysis}

Both primary and secondary methods will be used for the collection of required data. For the identification of the barriers faced by women entrepreneurs, researcher has utilized secondary method of collecting data. While, for the identification of the impact of entrepreneurial activities on the lifestyle of women researcher has opted to conduct a brief survey using a close-ended questionnaire. 


\section{Research Sample Profile}

A sample of 98 women entrepreneurs have been collected using snowball sampling methods from four different towns of Karachi, including Malir, Landhi, Korangi and Shah Faisal. Respondents were from the age group of 20-40, and most of them were literate and only few of them have completed intermediate or graduation. Majority of the sample population were either married, divorcee, widow or separated while only 14 percent were single.

\section{Average Monthly Income of Women Operating Small Business}

During the survey, first of all respondents were asked to identify their monthly income. From the responses it was established that income of women entrepreneurs from small business although is not very much high, but enough for them to support their daily expenses. The responses collected demonstrate that majority of the respondents are earning 7000 per month or more. This shows that the income of small entrepreneurs is increasing.

Table 1

Monthly Income

\begin{tabular}{|l|c|c|}
\hline Monthly Income & Frequency & Percentage \\
\hline $1000-2000$ & 14 & $14.2 \%$ \\
\hline $2001-3000$ & 9 & $9.2 \%$ \\
\hline $3001-4000$ & 10 & $10.2 \%$ \\
\hline $4001-5000$ & 12 & $12.3 \%$ \\
\hline $5001-6000$ & 8 & $8.2 \%$ \\
\hline 7000 or more & 45 & $45.9 \%$ \\
\hline Total & $\mathbf{9 8}$ & $\mathbf{1 0 0 \%}$ \\
\hline
\end{tabular}

\section{Spending Income Children Education}

Respondents were asked if they are spending their income on the education of the children in their family. It was established that women entrepreneurs have dedicated a proportion of their income for the education of children in their family, whereas, only $25.6 \%$ women do not prefer to spend their income on children education. The responses collected demonstrate that women encourage spending on children education.

Table 2

Children Education

\begin{tabular}{|l|c|c|}
\hline Spend on Child Education & Frequency & Percentage \\
\hline Yes & 73 & $74.4 \%$ \\
\hline No & 25 & $25.6 \%$ \\
\hline Total & $\mathbf{9 8}$ & $\mathbf{1 0 0 \%}$ \\
\hline
\end{tabular}




\section{Spending on House Maintenance}

Normally, women are considered more affectionate towards the maintaining and decorating their houses. In this context, it was asked if the respondents spend their income on the maintenance of their house. It was established that not all women entrepreneurs are very much passionate in maintaining their houses, as $46.9 \%$ of the respondents do not spend their income on house maintenance, while 53.1 percent of the respondents do spend on house maintenance.

\section{Table 3}

Spend on House Maintenance

\begin{tabular}{|l|c|c|}
\hline Spend on House Maintenance & Frequency & Percentage \\
\hline Yes & 52 & $53.1 \%$ \\
\hline No & 46 & $46.9 \%$ \\
\hline Total & $\mathbf{9 8}$ & $\mathbf{1 0 0 \%}$ \\
\hline
\end{tabular}

\section{Spending on Household Items}

In relation to the above question, this question was asked to inquire if women entrepreneurs spend their income on purchase of household items. It was established that majority of the sample population prefers to purchase household items from their income, while $32.7 \%$ do not make purchases for household items.

Table 4

Spend on Household Items

\begin{tabular}{|l|c|c|}
\hline Spend on Household Items & Frequency & Percentage \\
\hline Yes & 66 & $67.3 \%$ \\
\hline No & 32 & $32.7 \%$ \\
\hline Total & $\mathbf{9 8}$ & $\mathbf{1 0 0 \%}$ \\
\hline
\end{tabular}

\section{Spending on Food and Nutritions}

Women entrepreneurs were asked to identify if they spend their income on food and nutritional items. Healthy food is part of a good lifestyle, which is why this question helps researcher in examining if the lifestyle of small women entrepreneurs is changing or not? It was established from the responses that majority of the respondents spend their income on providing healthy food to their families, while only $11.3 \%$ cannot afford to do so. 

Entrepreneurial Activities on the Lifestyle of Women

Table 5

Spending on Food and Nutritions

\begin{tabular}{|l|c|c|}
\hline Spending on Food and Nutritions & Frequency & Percentage \\
\hline Yes & 87 & $88.7 \%$ \\
\hline No & 11 & $11.3 \%$ \\
\hline Total & $\mathbf{9 8}$ & $\mathbf{1 0 0 \%}$ \\
\hline
\end{tabular}

\section{Change after Starting Business}

This question was asked to inquire if any societal change has been observed by the respondents after starting the business. It was identified from the responses that majority of the respondents observed change in family status, while $21.4 \%$ of the respondents experiences that their status in society has increased, while $30.7 \%$ believe that after starting the business they can now provide education to their children.

Table 6

Change Observed After Starting Business

\begin{tabular}{|l|c|c|}
\hline $\begin{array}{l}\text { Change Observed After } \\
\text { Starting Business }\end{array}$ & Frequency & Percentage \\
\hline Family status change & 47 & $47.9 \%$ \\
\hline The status of women increase & 21 & $21.4 \%$ \\
\hline Children are getting educated & 30 & $30.7 \%$ \\
\hline Total & $\mathbf{9 8}$ & $\mathbf{1 0 0 \%}$ \\
\hline
\end{tabular}

\section{Discussion and Conclusions}

There are number of barriers which impede the growth and development of women entrepreneurship has been identified during the literature review. However, World Development Report of World Bank 2011 identifies the solution, which is perfectly applicable in context of Pakistan. It was established from the report that overall productivity of the world today can be increased by $25 \%$, if the discriminatory obstructions against women are taken care of. The removal of the discriminatory obstructions like inheritance and property law, access to financial institutions, limited time due to household chores and cultural practices will help in creating sustainable organizations operated by women. Despite the earlier stated benefit of the removal of discriminatory obstructions against women, this will also empower women in economic terms and will create gender equality, along with creating jobs and sustainable growth. However, only the removal of obstructions is not the solution of encouraging women entrepreneurship, but investment in this regard is also important. In fact, investment in new businesses run by women is considered one of the most effective methods of promoting equality and supporting sustainable and inclusive economic growth. Moreover, 
investing in programs specifically designed for women can have substantial impact on the overall development of society, since it is a known fact that women spend a large proportion of their income on the well-being, education and health of their communities and families compare to men. Despite the fact that targeted measures can help in bridging the gap for women, but the importance of removing discriminatory obstructions is must, since it impedes the complete participation of women in the society and economy.

Moreover, it was identified from the research that after engaging in entrepreneurial activities; the lifestyles of women entrepreneurs have changed substantially. Women are more empowered and liberated and can take independent decisions. From the responses obtained, it was identified that women entrepreneurs from their earnings are able to provide better education to their children along with providing healthy food to their families. Moreover, from their earnings women are also maintaining their house and making purchase of household products to ease their work. Conclusively, it can be said that lifestyle of women is substantially improved after starting a business.

\section{References}

Bowen, D. D. \& Hisrich, R. D. (1986). The Female Entrepreneur: A Career Development Perspective In Academy of management review, Volume No. 11, Issue No. 2, pp, 393-407.

Brush,G., Carter, M., Gatewood, J., Greene, G. \& Hart, M. (2006). Growth Oriented Women Entrepreneurs And Their Businesses: A Global Research Perspective, Cheltenham, UK: Edward Elgar Publishing Ltd.

Carter, S. \& Jones-Evans, D. (2006). Enterprise And Small Business: Principles, Practice And Policy. Pearson Education.

Esperança, J. P., Hill, M. M. \& Valente, A. C. (2006). Entry Mode And HRM Strategies Of Emerging Multinationals: An Empirical Analysis Of Portuguese Firms Entering The Spanish Market In International Journal of Organizational Analysis, Volume No. 14, Issue No. 4, pp, 260-276.

Global Entrepreneurship Monitor. (2007). Report On Women And Entrepreneurship. GEM, retrieved from: http://www.gemconsortium.org/docs/download/281.

Goheer, N. A. (2003). Women Entrepreneurs In Pakistan. How To Improve Their Bargaining Power, Gilani Foundation.

Gundry. L. K., Ben-Yoseph. M. \& Posig. M. (2002). Contemporary Perspectives On Women's Entrepreneurship: A Review \& Strategic Recommendation In Journal of Enterprising Culture. Volume No. 10, Issue No. 1. pp, 67-86. 

Entrepreneurial Activities on the Lifestyle of Women

Hisrich, R. \& Ozturk, S. (1999). Women Entrepreneurs In A Developing Economy In The Journal of Management Development, Volume No. 18, Issue No. 2, pp, 114-25.

Kalim, Ayesha (2012). Women Entrepreneurship The Emerging Workforce in 21st Century: Turning Challenges into Opportunities. Innovative Educational Solutions (IES), Lahore; Proceedings of 2nd International Conference on Business Management

Kamal, S. (1997). Women, Empowerment And Poverty Alleviation In South Asia: The Dual Benefits Of Microcredit. p, 114, South Asia Poverty Alleviation Program, UNDP

Keeves, J. P. (1997). Educational Research, Methodology And Measurement: An International Handbook (2nd ed.). New York, N.Y.: Paragon.

Kothari, C. R. (2004). Research Methodology Methods \& Techniques (2nd rev. ed.). New Delhi: New Age International (P) Ltd.

Mahmood, B., Sohail, M., Khalid, S., et al. (2012). Gender Specific Barriers to Female Entrepreneurs in Pakistan: A Study in Urban Areas of Pakistan In British Journal of Education, Society \& Behavioural Science, ISSN: 2278 - 0998, Vol. 2, Issue: 4.

Muhammad, A. R. (2008). Barriers To Development And Progression Of Women Entrepreneurs In Pakistan In Journal of entrepreneurship, Volume No. 17, Issue No. 1, pp, 59-72

Schumpeter, J. A. (2000). Entrepreneurship As Innovation. Entrepreneurship In The Social Science View, pp, 51-75.

Shane, S. \& Venkataraman, S. (2000). The Promise Of Entrepreneurship As A Field Of Research In Academy Of Management Review, Volume No. 25, Issue No. 1, pp, 217-226.

World Bank (2011). World Development Report. World Bank, http://wdronline. worldbank.org/includes/imp_images/book_pdf/WDR_2011.pdf

World Bank (2012). Less than 25\% of Pakistani Women Entrepreneurs Use Microfinance Loans, Finds The World Bank. World Bank, retrieved from: http:/www.worldbank. org/en/news/press-release/2012/10/17/less-than-25percent-of-pakistani-womenentrepreneurs-use-microfinance-loans-finds-the-world-bank

Samina Rauf is Assistant Professor in the Department of Social Work, University of Karachi.

Dr. Nasreen Aslam Shah is Professor in the Department of Social Work \& Director of the Centre of Excellence for Women's Studies, University of Karachi. 